Joanne Guay MD FRCPC, * Margaret Haig MD FRCPC, * Louise Lortie RN,* Marie-Claude Guertin, $\ddagger$ Benoit Poitras MD FRCPC $\dagger$

\title{
Predicting blood loss in surgery for idiopathic scoliosis
}

The authors attempted to determine the relative importance of factors that influence bleeding during and after spinal fusion. Data from 30 ASA I patients with idiopathic scoliosis were prospectively collected and analyzed. Intraoperative bleeding was $1971 \pm 831 \mathrm{ml}$ (mean $\pm S D)(61.5 \pm 27 \%$ of estimated blood volume (EBV) and correlated with the number of fused vertebrae $(r=0.66, P<0.0001)$ and the duration of surgery $(r=0.46, P=0.0105)$. There was no correlation between intraoperative bleeding and the Cobb curve angle (43 to $\left.86^{\circ}\right)$, the mean arterial blood pressure (MAP) (63 to $86 \mathrm{mmHg}$ ), the central venous pressure (CVP), the quantity of epinephrine infiltrated, muscle relaxants or opioids used, nor in the type of opioids used, the minimal body temperature or whether stored or autologous blood was used. Postoperative bleeding was $1383 \pm 369 \mathrm{ml}(43.1 \pm 11.7 \%$ of $\mathrm{EBV})$ and correlated with the length of time the Hemovac drain was in place ( $r$ $=0.40, P=0.0285)$ and $M A P(r=0.40, P=0.0285)$. There was no correlation between postoperative and intraoperative bleeding nor in the number of fused vertebrae. Six patients had greater postoperative than intraoperative bleeding. The total bleeding (intra-plus postoperative) was $3347 \pm 920 \mathrm{ml}$ (104.2 \pm 30.6 of EBV) and correlated with the number of fused vertebrae ( $r=0.63, P=0.0001$ ) and with the duration of surgery ( $r=0.42, P=0.0208$ ). We conclude that the number of fused vertebrae is the key factor in predicting intraoperative and total bleeding. Postoperative bleeding is considerable (up to $76.9 \%$ of EBV). No other factors allow for adequate prediction of

\section{Key words}

ANAESTHESIA: paediatric;

BLOOD: loSS;

SURGERY: orthopaedic.

From the Departments of Anesthesiology* and Surgery†, Ste-Justine Hospital and the University of Montreal, and the Department of Mathematics and Statistics University of Montrealł, Montreal, Quebec, Canada. Presented at the 50th Annual Meeting of the Canadian Anaesthetists' Society, Halifax, June 4-8, 1993.

Address correspondence to: Dr. Joanne Guay, Department of Anesthesiology, Sainte-Justine Hospital, 3175 Côte Ste-Catherine Road, Montreal, Quebec H3T 1C5 Canada. Accepted for publication 3rd June, 1994. postoperative bleeding and these patients must be kept under strict surveillance after surgery.

Cette étude avait pour but de déterminer limportance relative des facteurs qui influencent les pertes sanguines per et postopératoires au cours des arthrodèses vertébrales postérieures. Les données de 30 patients porteurs de scoliose idiopathique ont été recueillies prospectivement puis analysées. Le saignement intraopératoire était de $1971 \pm 831 \mathrm{ml}$ (moyenne $\pm D S$ ) $(61.5 \pm 27 \%$ du volume sanguin estimé (VSE)) et était relié au nombre de vertèbres fusionnées $(r=0.66, P<0.0001$ ) et à la durée de la chirurgie ( $r=0.46, P=0.0105)$. Le saignement intraopératoire n'était pas relié au degré de courbure $\left(43\right.$ à $\left.86^{\circ}\right)$, ni à la pression artérielle moyenne (PAM) (63 à $86 \mathrm{~mm} \mathrm{Hg}$ ), à la pression veineuse centrale (PVC), à la quantité d'épinéphrine, de relaxants neuro-musculaires ou de morphiniques utilisés, ni à la sorte de morphinique utilisé, à la temperature corporelle minimale ou au type de sang administré. Le saignement past-opératoire était de $1383 \pm 369 \mathrm{ml}(43.1$ $\pm 11.7 \%$ du VSE) et était relié à la durée du maintien d'un drain $(r=0.40, P=0.0285)$ et à la $P A M(r=0.40, P=$ $0.0285)$. Le saignement post-opératoire n'était pas relié au saignement intra-opératoire ni au nombre de vertèbres fusionnées. Six patients ont eu un saignement post-opératoire supérieur au saignement intra-opératoire. Le saignement total (intra et postopératoire) était de $3347 \pm 920 \mathrm{ml}$ (104.2 $\pm 30.6 \% \mathrm{du}$ VSE) et était relié au nombre de vertèbres fusionnées $(r=0.63$, $P=0.0001$ ) ainsi qu'à la durée de la chirurgie $(r=0.42$, $P=0.0208$ ). Nous concluons que le nombre de vertèbres fusionnées est le meilleur facteur pour prédire le saignement intraopératoire et le saignement total. Le saignement post-opératoire est élevé (jusqu'à $76.9 \%$ du VSE). Il n'y a pas d'autre facteur utile pouvant prédire le saignement post-opératoire et tous les patients doivent être surveillés étroitement en post-opératoire.

Blood loss' during and after spinal fusion for correction of idiopathic scoliosis is high and often as much or more than the patient's total estimated blood volume (EBV). ${ }^{1-3}$ In some patients, haemostatic abnormalities may increase the bleeding problem. Despite a bleeding time that is usually within the normal range, half of the patients with idiopathic scoliosis have abnormal platelets with a decreased aggregation in response to epinephrine and ad- 
enosine diphosphate. ${ }^{4}$ Furthermore, the collagen from patients with idiopathic scoliosis aggregates platelets only one-fourth as efficiently as the collagen from normal patients. ${ }^{5}$

Many anaesthetic and surgical techniques have been cited as possible factors influencing the blood loss during surgery including: extent of dissection, number of fused vertebrae, duration of surgery, surgical technique used, type of instrumentation, site and size of bone graft and phase of operation in which it is obtained, use of epinephrine, degree of muscle relaxation, mean arterial blood pressure and pressure in the inferior vena cava. ${ }^{6-8}$ However, few recent studies have clarified the relative importance of these factors and none has tried to define the factors which influence postoperative blood loss. ${ }^{6,7}$ The aim of this study was to determine the relative importance of factors that influence bleeding during and after surgery in patients undergoing spinal fusion for idiopathic scoliosis.

\section{Methods}

After approval by the ethics committee, data from 30 ASA I patients who underwent spinal fusion by the same surgeon using a Cottrel-Dubousset surgical technique with harvesting of bone graft from the iliac crest were collected prospectively. No patients had a coagulation abnormality (bleeding time > nine minutes) and they were positioned on a Harrington frame. The anaesthetist in charge of the patient chose the anaesthetic technique. Opioids were administered to obtain a low normotensive anaesthesia with an inspired isoflurane concentration of $2.0 \%$ or less. The criteria for administration of neuromuscular relaxants varied widely as some anaesthetists used only two doses of pancuronium, i.e., one to facilitate tracheal intubation and one after the wake-up test, while others tried to maintain a moderate blockade as defined by obtaining two or three responses to a train-of-four stimulation. During surgery, patients were monitored with an ECG (Datascope 2002), pulse oximeter (Omehda Biox 3700), capnometer (Datex Normocap 200), automated oscillometric blood pressure device (Dinamapp ${ }^{\circledR}$ ) and a nasopharyngeal thermistor connected to the cardioscope. An arterial catheter was placed in the radial artery (\#20-gauge) and a central venous catheter introduced into the right internal jugular vein (\#16-gauge) (Datascope 2002). Heart rate and blood pressure were recorded before the induction of anaesthesia and every five minutes thereafter until the end of anaesthesia. Central venous pressure, temperature and urine output were recorded every hour during surgery. Appropriate minute ventilation and fresh gas flows were calculated in order to maintain normocarbia using a coaxial circuit. Maintenance fluid requirements and estimated third space losses were replaced with lactated Ringer's solution 6 to $10 \mathrm{ml} \cdot \mathrm{kg}^{-1} \cdot \mathrm{hr}^{-1}$ to maintain the central venous pressure between 4 and $8 \mathrm{mmHg}$. Surgical blood losses were replaced with lactated Ringer's solution up to 20 to $30 \%$ of the estimated blood volume in a ratio of $3: 1$, and with packed red blood cells diluted in normal saline or banked autologous blood for blood losses exceeding 20 to $30 \%$ of the estimated blood volume. For patients with homologous blood transfusion, each unit of packed red blood cells was diluted with $250 \mathrm{ml}$ saline and fresh frozen plasma was administered after the loss of 50 to $100 \%$ of the estimated blood volume.

The skin was infiltrated with 20 to $250 \mathrm{ml}$ epinephrine $1: 1,000,000$. Exposure of the bony elements was done from the upper to the lower vertebrae. After harvesting cortical and cancellous bone from the right iliac crest, hooks were inserted. Decortication of laminae, facet joints and transverse processes was done at every level and rods were inserted with $a^{\prime}$ derotation manoeuvre as indicated. A wake-up test was performed and bone graft was packed at all levels to be fused. Hemovac drainage was inserted before closure and left in place until the bleeding tapered to $<100 \mathrm{ml}$ in the preceding eight hours. Following surgery, urine output was monitored and vital signs were recorded including blood pressure as measured by auscultation of Korotkoff sounds.

The following data were collected: age, sex, weight, height, Cobb's curve angle, number of fused vertebrae, duration of anaesthesia and surgery, quantity of narcotics used, quantity of muscle relaxants administered, minimal intraoperative central core temperature, mean arterial blood pressure and mean central venous pressure maintained during surgery, quantity of cristalloids administered and hourly urine output. The Cobb's curve angle is measured as follows. The upper and lower end vertebrae are determined. These are the vertebrae which tilt most toward the concavity of the curve. A horizontal line is drawn at the superior border of the highest vertebral body and another is drawn at the inferior border of the lowest vertebral body. Perpendiculars to these lines are drawn and the angle of intersection is measured. The more severe the curve the greater the Cobb angle.

Intraoperative blood loss was measured by weighing sponges and suction draining. Wound drainage (Snyder, Hemovac) was measured postoperatively every eight hours for the first $24 \mathrm{hr}$ (i.e., to 8 am the day following surgery) and until drains were removed. The type and quantity of blood products administered during and after surgery, the urine output for the first $24 \mathrm{hr}$, the first mobilisation following surgery and the number of in-hospital days were also noted. The following variables were calculated; estimated blood volume at $60 \mathrm{ml} \cdot \mathrm{kg}^{-1}$ for females and at $65 \mathrm{ml} \cdot \mathrm{kg}^{-1}$ for males, intraoperative, post- 
operative and total blood losses as a percentage of estimated blood volume, the intraoperative quantity of opioids in $\mu \mathrm{g} \cdot \mathrm{kg}^{-1}$, muscle relaxants (pancuronium) in $\mathrm{mg} \cdot \mathrm{kg}^{-1} \cdot \mathrm{hr}^{-1}$, total intraoperative quantity of crystalloids in $\mathrm{ml} \cdot \mathrm{kg}^{-1}$, the urine output during surgery in $\mathrm{ml} \cdot \mathrm{kg}^{-1} \cdot \mathrm{hr}^{-1}$ and postoperative urine output in $\mathrm{ml} \cdot \mathrm{kg}^{-1}$ at $8 \mathrm{am} .{ }^{9}$ In order to allow correlation trials between the quantity of opioid and the other variables, the quantity of sufentanil was multiplied by seven. The relative potency of sufentanil compared with fentanyl is estimated to be between five and ten. ${ }^{10,11}$ Relationships between variables were analyzed using stepwise regression. Statistical differences were assessed using Student's $\mathrm{t}$ test or Mann-Whitney where appropriate. A $P<0.05$ was considered significant. For linear regression, this corresponds to a correlation coefficient ( $r$ value) of approximately 0.361 .

\section{Results}

General patient data are included in Table I. Twentythree patients received fentanyl: $16.0 \pm 3.3 \mu \mathrm{g} \cdot \mathrm{kg}^{-1}$ (mean \pm SD) and seven patients received sufentanil: 2.9 $\pm 0.4 \mu \mathrm{g} \cdot \mathrm{kg}^{-1}$ during surgery. Pancuronium $0.17 \pm 0.06$ $\mathrm{mg} \cdot \mathrm{kg}^{-1}$ (from 0.09 to $0.34 \mathrm{mg} \cdot \mathrm{kg}^{-1}$ ), isoflurane and nitrous oxide was used in all patients. Twenty-two patients received autologous blood while eight received homologous blood. Of the 22 who received autologous blood, three were also given homologous blood in the intra- and postoperative period. Four patients receiving homologous blood were given one plasma unit during surgery. The volume of blood loss during and after the surgery, the total amount until the removal of drains, and the quantity of blood products administered are indicated in Table II.

There was a correlation between the intraoperative bleeding as an absolute amount or as a percentage of the EBV and the number of fused vertebrae $(\mathrm{r}=0.66$, $P=0.00008$, and $\mathrm{r}=0.56, P=0.0013$ ) (Figure 1), the duration of surgery $(\mathrm{r}=0.46, P=0.0105$ and $\mathrm{r}$ $=0.41, P=0.0244$ ) and the volume of blood administered during that period $(\mathrm{r}=0.93, P<0.0001$ and $\mathrm{r}=0.40, P=0.0285$ ). There was no correlation between the intraoperative bleeding in absolute value or as a percentage of EBV and the Cobb curve angle, the mean arterial blood pressure maintained during surgery (MAP), the central venous pressure (CVP), the quantity of epinephrine, muscle relaxants or opioids used or the minimal core temperature recorded during surgery. Twelve patients had a MAP ranging between 63 and $70 \mathrm{mmHg}(66.3 \pm 3.0 \mathrm{mmHg})$ and 18 patients had MAP ranging between 71 and $86 \mathrm{mmHg}(76.5 \pm 4.4 \mathrm{mmHg})$ $(P<0.001)$. Intraoperative bleeding in patients with a MAP lower than or equal to $70 \mathrm{mmHg}$ was comparable
TABLE I General data patients

\begin{tabular}{lcc}
\hline & Mean $\pm S D$ & (Range) \\
\hline Age (yr) & $15 \pm 2.1$ & $(12-20)$ \\
Sex & $29 \mathrm{~F}: 1 \mathrm{M}$ & \\
Weight (kg) & $49 \pm 6.2$ & $(37.5-65)$ \\
Cobb curve angle ( $)$ & $55.4 \pm 9.3$ & $(43-86)$ \\
Number of fused vertebrae & $9.3 \pm 1.4$ & $(7-13)$ \\
Epinephrine used (ml of $\mathrm{l:}$ & & \\
$\quad$ l,000,000) & $154 \pm 51$ & $(70-250)$ \\
Duration of surgery (hr) & $4.1 \pm 0.6$ & $(3-5.6)$ \\
Mean arterial blood pressure & & \\
$\quad$ maintained during surgery & & \\
$\quad$ (mmHg) & $72.4 \pm 6.4$ & $(63-86)$ \\
Mean central venous pressure & & \\
$\quad$ maintained during surgery & & \\
$\quad$ (mmHg) & $5.8 \pm 2.6$ & $(1.1-13.2)$ \\
Minimal core temperature $\left({ }^{\circ} \mathrm{C}\right)$ & $34.6 \pm 0.7$ & $(33.3-36.4)$ \\
Duration of Hemovac (hr) & $51.8 \pm 11.3$ & $(42-74.8)$ \\
First mobilization (post-op day) & $4.6 \pm 1.8$ & $3-11$ \\
Duration of hospitalization (days) & $9.0 \pm 1.8$ & $(7-14)$ \\
Blood loss per number of fused & & \\
$\quad$ vertebrae: & & \\
- Peroperative & $208.9 \pm 68.0$ & $(87.9-362.5)$ \\
- Postoperative & $152.2 \pm 47.6$ & $(45.9-256.4)$ \\
- Total & $365.2 \pm 76.5$ & $(223.9-503.3)$ \\
\hline$\quad$ & &
\end{tabular}

to that of patients with a MAP higher than $70 \mathrm{mmHg}$ that is $2158 \pm 908 \mathrm{ml}$ compared with $1982 \pm 841 \mathrm{ml}$ or $222 \pm 70 \mathrm{ml}$ per fused vertebrae vs $200 \pm 67 \mathrm{ml}$. The intraoperative bleeding in $\mathrm{ml}$ or as a percentage of EBV and the volume of blood administered of patients receiving fentanyl was similar to that of patients receiving sufentanil. Likewise transfusion of homologous vs autologous blood did not change the intraoperative bleeding (Table II).

Postoperative bleeding from the end of surgery to drain removal, in total volume or as a percentage of EBV correlated poorly with the duration the drain was in place ( $\mathrm{r}=0.38, P=0.0383$ and $\mathrm{r}=0.40, P=0.0285$ ) and with MAP maintained during surgery $(\mathrm{r}=0.40, P=$ 0.0285 ). There was no correlation between blood losses during the first $24 \mathrm{hr}$ after surgery and MAP measured during that time. No correlation was found between the total postoperative bleeding in absolute value or as a percentage of EBV and any other variable studied including the number of fused vertebrae and blood loss during surgery. Six patients had greater postoperative than intraoperative bleeding, ranging from 1135 to $2268 \mathrm{ml}(33.3$ to $76.9 \%$ of EBV) compared with intraoperative bleeding of 615 to $1750 \mathrm{ml}$ (19.8 to $48.6 \%$ of EBV). Choice of opioid (fentanyl or sufentanil) did not influence postoperative bleeding in total volume or as a percentage of EBV (Table II). The transfusion of autologous or homologous blood did not change postoperative blood loss 


\begin{tabular}{|c|c|c|c|c|c|}
\hline & \multirow[b]{2}{*}{$\begin{array}{l}\text { All patients } \\
(n=30)\end{array}$} & \multicolumn{2}{|l|}{ Opioid used } & \multicolumn{2}{|c|}{ Blood replacement } \\
\hline & & $\begin{array}{l}\text { Fentanyl } \\
(n=23)\end{array}$ & $\begin{array}{l}\text { Sufentanil } \\
(n=7)\end{array}$ & $\begin{array}{l}\text { Autologous } \\
(n=22)\end{array}$ & $\begin{array}{l}\text { Homologous } \\
(n=8)\end{array}$ \\
\hline Peroperative blood loss (ml) & $1971 \pm 831$ & $1987 \pm 768$ & $1915 \pm 1080$ & $1960 \pm 907$ & $2000 \pm 626$ \\
\hline Peroperative blood loss (\% of EBV) & $61.5 \pm 27.6$ & $63.1 \pm 24.8$ & $56.0 \pm 37.0$ & $59.5 \pm 30.1$ & $66.7 \pm 19.6$ \\
\hline Blood administered during surgery $(\mathrm{ml})$ & $1481 \pm 787$ & $1551 \pm 730$ & $1250 \pm 978$ & $1358 \pm 759$ & $1625 \pm 694$ \\
\hline Postoperative blood loss (ml) & $1383 \pm 369$ & $1332 \pm 375$ & $1551 \pm 315$ & $1382 \pm 415$ & $1387 \pm 217$ \\
\hline Postoperative blood loss (\% of EBV) & $43.1 \pm 11.7$ & $42.7 \pm 12.8$ & $44.3 \pm 7.6$ & $41.9 \pm 13.2$ & $46.1 \pm 5.6$ \\
\hline Blood administered after surgery (ml) & $770 \pm 426$ & $717 \pm 328$ & $943 \pm 663$ & $880 \pm 408^{*}$ & $469 \pm 339^{*}$ \\
\hline Total blood loss (ml) & $3347 \pm 920$ & $3320 \pm 884$ & $3468 \pm 1035$ & $3343 \pm 986$ & $3387 \pm 689$ \\
\hline Total blood loss (\% of EBV) & $104.2 \pm 30.6$ & $106.0 \pm 29.1$ & $100.3 \pm 35.7$ & $101.7 \pm 32.9$ & $112.8 \pm 20.2$ \\
\hline Total blood administered (ml) & $2231 \pm 808$ & $2205 \pm 730$ & $2121 \pm 106$ & $2309 \pm 764$ & $2094 \pm 823$ \\
\hline
\end{tabular}

Mean \pm SD.

*These two values are different, $P<0.05$.

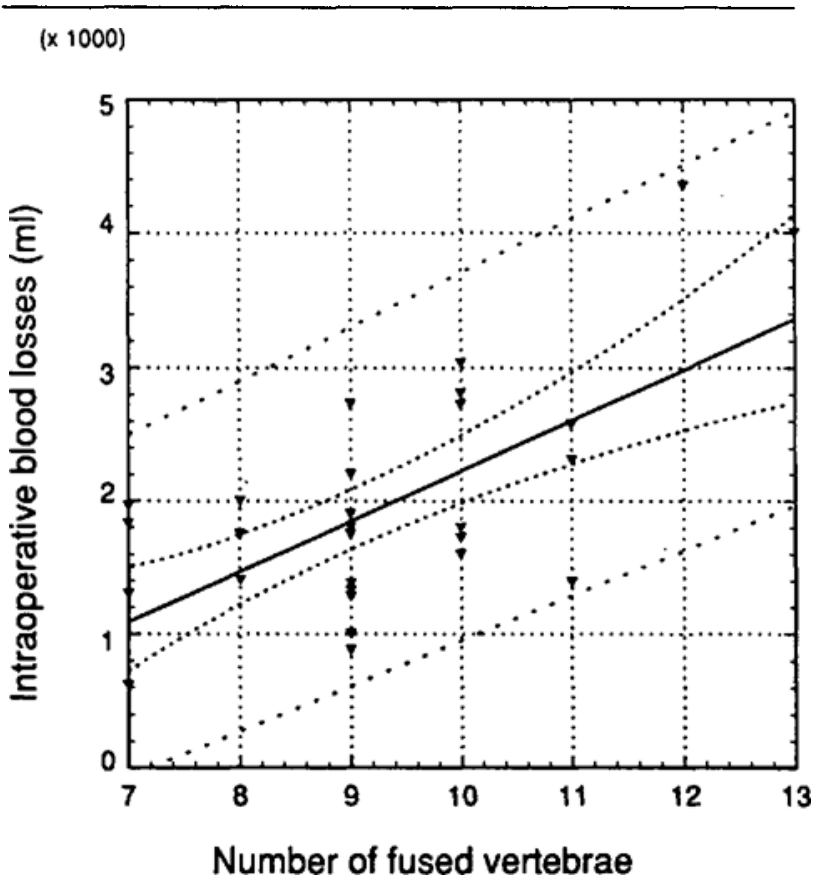

FIGURE 1 Correlation between intraoperative blood losses and the number of fused vertebrae. $\mathrm{r}=0.66, P<0.0001$.

volume but did affect the amount of blood transfused in the postoperative period $(P=0.02)$ (Table II).

The total blood loss, i.e., intra- plus postoperative up to drain removal, in absolute value or as a percentage of $\mathrm{EBV}$, was correlated to the number of fused vertebrae ( $\mathrm{r}=0.63, P=0.0001$ and $\mathrm{r}=0.47, P=0.0088$ ) (Figure 2) and also to the duration of surgery ( $\mathrm{r}=0.42, P=$ 0.0208). There was also a correlation between the quantity of blood given during surgery and total bleeding in absolute value $(\mathrm{r}=0.76, P<0.0001)$. Timing of first mobilization and duration of hospital stay were not corre-

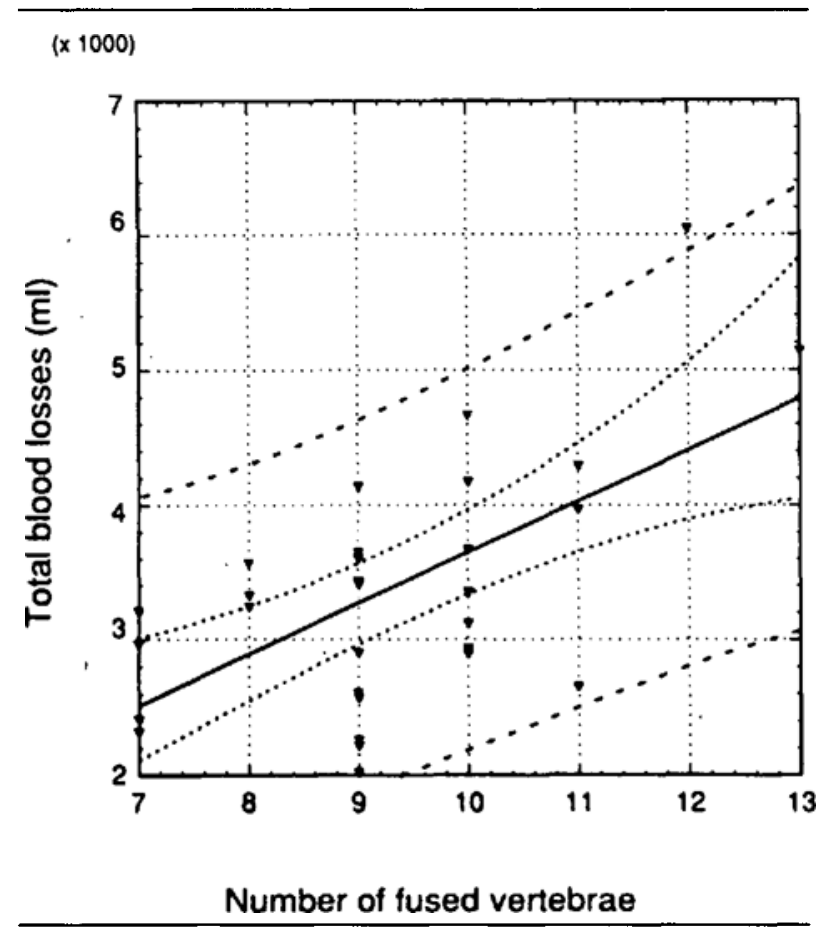

FIGURE 2 Correlation between total blood losses and the number of fused vertebrae. $\mathrm{r}=0.63, P=0.0001$.

lated with blood loss, during the pre- or postoperative period.

\section{Discussion}

In this study the number of fused vertebrae was the most important factor in predicting intraoperative and total blood loss in patients undergoing posterior spinal fusion of seven to thirteen vertebrae for correction of idiopathic scoliosis ( $\mathrm{r}=0.66, P<0.0001$ and $0.63 P=0.0001)$ (Figures 1 and 2). A correlation between intraoperative bleeding and the number of fused vertebrae has been 
reported for patients with idiopathic scoliosis as well as for patients with scoliosis secondary to neuromuscular disease. ${ }^{12,13}$ However, a correlation between the number of fused vertebrae and total blood loss, i.e., including the postoperative period as found in the present study, could be more helpful in improving prediction of the quantity of blood products required for the intervention. Preoperative autologous blood collection makes possible a reduction in the use of homologous blood. ${ }^{14}$ This technique requires a great investment by both patients and hospital blood banks. A preliminary estimate of the quantity of blood needed for surgery might prove useful for the patient by reducing the number of blood units he would have to donate or help predict which patients will likely need additional homologous blood. Nevertheless this prediction can only be approximate since total bleeding per vertebrae varied widely from 223.9 to $503.3 \mathrm{ml}$ (Table I).

The quantity of blood lost per vertebra noted in this study may differ from other institutions. All surgery was performed by the same-surgeon. Although in a previous study we detected no noticeable difference in bleeding volume when surgery was performed by either of two experienced surgeons, Pouliquen et al. have reported that the duration of surgery and blood loss are less if the segmental posterior instrumentation as described by Cottrel and Dubousset was performed by their most experienced surgeon, that is, $171 \pm 38 \mathrm{~min}$ and $1082 \pm 614$ $\mathrm{ml}$ compared with $225 \pm 46 \mathrm{~min}$ and $1781 \pm 1157 \mathrm{ml}$.,15 $^{1}$ The use of homologous or synthetic bone graft, instead of the harvesting of bone from the iliac crest might also have decreased the intraoperative bleeding from $1828 \pm$ 1086 to $1120 \pm 721 \mathrm{ml}^{15}$

In this study, the duration of surgery correlated both with intraoperative and total bleeding ( $\mathrm{r}=0.46, P=$ 0.0105 and $0.42, P=0.0208$ ). This correlation was also found by Murat et al. for idiopathic scoliosis and by Fromes and Morin for neuromuscular scoliosis. ${ }^{12,13}$ A correlation between these two factors does not indicate which is the causal factor since major bleeding could slow the progress of surgery. The duration of surgery nevertheless reflects the surgeon's skill which is a determining factor of the intraoperative bleeding. ${ }^{15}$ Since the duration of surgery cannot be established beforehand, it cannot be used to predict blood losses.

There was no correlation between blood loss and the Cobb curve angle in the range between 43 and $86^{\circ}$. These results confirm the study of McNeil et al. who did not find a difference in blood loss in patients with Cobb curve angles less than $60_{-}^{\circ}$, between 60 to $79^{\circ}$ or greater than $790^{\circ} 16$

There was no correlation between the intraoperative blood losses and the quantity of epinephrine used. All patients received epinephrine, the quantity administered being determined by the surgeon based on the length of incision and height of patient; which implies that each patient received an appropriate quantity. From this study it was not possible to make any inference on the efficacy or lack of efficacy of epinephrine.

Some authors have recommended complete muscle relaxation for the entire duration of surgery to reduce intraabdominal pressure, and hence reduce bleeding. ${ }^{7}$ In this study, there was no correlation between intraoperative bleeding and the quantity of muscle relaxants given. However, with the protocol used in this study, no definite conclusions can be drawn on the effects of a profound neuromuscular relaxation on bleeding.

The volume of intraoperative bleeding was not related to the mean arterial pressure maintained during surgery, in the range between 63 and $86 \mathrm{mmHg}$. At first glance this may seem surprising since the use of controlled hypotension has already been reported as decreasing intraoperative blood losses in patients undergoing spinal fusion for idiopathic and non-idiopathic scoliosis. ${ }^{16-21}$ However, the exact level at which the MAP should be maintained is not clear. In a retrospective study, Lawhon et al., demonstrated that the intraoperative bleeding was reduced if the MAP was maintained below $90 \mathrm{mmHg}$ compared with over $90 \mathrm{mmHg}$, but found no extra benefit in lowering the MAP further. ${ }^{17}$

The clinical benefit of hypotensive techniques for scoliosis surgery might not be as important as originally thought. Bennett and Abbott reported that lowering the systolic blood pressure to $75 \pm 5 \mathrm{mmHg}$ reduced bleeding from $19.55 \pm 11.6$ to $12.84 \pm 9.08 \%$ of EBV. ${ }^{19}$ The benefit of a mean reduction in blood loss of $6.6 \%$ of EBV or approximately $180 \mathrm{ml}$ for a patient weighing $50 \mathrm{~kg}$ is doubtful since it would probably not reduce by even one unit the quantity of blood transfused. According to our results the intraoperative bleeding of patients with a MAP of $76 \mathrm{mmHg}$ is comparable to that of patients with a MAP of $66 \mathrm{mmHg}$, that is $1982 \pm 841$ vs $2158 \pm 908$ $\mathrm{ml}$ or $200 \pm 67$ vs $222 \pm 70 \mathrm{ml}$ per fused vertebra. These results are similar to those of Porter $e t$ al. described under controlled hypotension, between 60 and $70 \mathrm{mmHg}$ with nitroprusside, captopril-nitroprusside or nitroglycerin, that is 2200,2783 and $1068 \mathrm{ml}$ or 178,236 and $166 \mathrm{ml}$ per fused vertebra and almost identical to the Bennett's hypotensive group with either pentolinium, pentolinium-halothane-propranolol or nitroprussidepropranolol that is $223 \mathrm{ml}$ per fused vertebra. ${ }^{20,22}$

It is also possible that the aetiology of hypotension, i.e., lowering of cardiac output vs lowering peripheral resistance, is an important factor in the efficacy of hypotension on the reduction of intraoperative bleeding in patients undergoing posterior spinal fusion. In a study 
where pentolinium and propranolol were used to achieve hypotension, Knight et al. reported that the sole haemodynamic variable related to intraoperative bleeding was the left ventricular stroke work index. ${ }^{23}$ Since it is possible that hypotension increases the risks of neurological sequelae, particularly if one uses an agent which lowers spinal blood flow such as trimethaphan, the risk:benefit ratio of the various hypotensive techniques reported in the literature needs to be clearly defined. ${ }^{24-26}$

The mean postoperative bleeding in scoliosis patients is high that is $1383 \pm 369 \mathrm{ml}$ or $43.1 \pm 11.7 \%$ of EBV and in fact exceeded intraoperative bleeding in $20 \%$ of patients. Postoperative bleeding is related to the length of time the Hemovac drain is kept in place ( $\mathrm{r} 0.40, P$ $=0.0285$ ). This is not surprising since the surgeon leaves the drain until the bleeding tapers off to less than 100 $\mathrm{ml}$ in the preceding eight hours. It is possible, however, that the continuous postoperative drainage encourages bleeding by creating a cavity where blood may accumulate. The absence of a drain did not eliminate postoperative bleeding. In centres where postoperative drainage is not used, a decrease in haematocrit sufficient to necessitate blood transfusion can occur up to the third operative day. ${ }^{12,13}$ Furthermore the absence of a drain increases the risk of severe haematoma formation. ${ }^{15}$

Postoperative bleeding was correlated with the MAP maintained during surgery ( $\mathrm{r} 0.40, P=0.0285$ ). A decrease in postoperative bleeding in patients with intraoperative controlled hypotension has been noted by Malcolm-Smith et al., that is $533 \pm 267$ vs $1014 \pm 558 .^{18}$ In that study the intraoperative bleeding of patients under controlled hypotension was less than in the control group that is $525 \pm 226$ vs $1530 \pm 941 .^{18}$ The reduced intraoperative bleeding of the hypotensive group might have resulted in less dilutional thrombocytopenia and higher levels of coagulation factors in the immediate postoperative period. In the present study, however, the correlation between postoperative bleeding and the intraoperative MAP could not have resulted from a lesser dilution of the coagulation factors in these patients since the postoperative bleeding was not related to the intraoperative bleeding and furthermore the intraoperative bleeding of patients with a MAP $<70 \mathrm{mmHg}$ was similar to the bleeding in patients with MAP $>70 \mathrm{mmHg}$. More studies are needed to confirm this correlation.

The absence of correlation between postoperative bleeding and the number of fused vertebrae or intraoperative bleeding make it impossible to predict the amount of postoperative bleeding. These patients must be kept under strict surveillance following surgery even if the intraoperative bleeding has been minimal.

In conclusion, the number of fused vertebrae is the most important factor in predicting intraoperative and total bleeding, that is until drain removal. Postoperative bleeding exceeds intraoperative bleeding in $20 \%$ of patients and cannot be predicted by the number of fused vertebrae nor the intraoperative bleeding.

\section{Acknowledgements}

The authors wish to thank Dr. Jean-Claude Jéquier for his help to the elaboration of the research protocol and the interpretation of the results, and Gilles Ducharme $\mathrm{PhD}$ who supervised Mrs. Guertin for the statistical analysis. These services were made possible through special funding from the FRSQ and the Interservice Club Council granted to the GRECE at the Ste-Justine Hospital Research Center.

\section{References}

1 Guay J, Reinberg C, Poitras B, et al. A trial of desmopressin to reduce blood loss in patients undergoing spinal fusion for idiopathic scoliosis. Anesth Analg 1992; 75: 405-10.

2 Relton JES, Conn AW. Anaesthesia for the surgical correction of scoliosis by the Harrington method in children. Can Anaesth Soc J 1963; 10: 603-15.

3 Relton JES, Hall JE. An operation frame for spinal fusion: a new apparatus designed to reduce haemorrhage during operation. J Bone Joint Surg Br 1967; 49; 327-32.

4 Yarom R, Muhlrad A, Hodges S, Robin GC. Platelet pathology in patients with idiopathic scoliosis: ultrastructural morphometry, aggregations, $x$-ray spectrometry, and biochemical analysis. Lab Invest 1980; 43: 208-16.

5 Uden A, Nilsson IM, Willner S. Collagen-induced platelet aggregation and bleeding time in adolescent idiopathic scoliosis. Acta Orthop Scand 1980; 51: 773-7.

6 Phillips WA, Hensinger RN. Control of blood loss during scoliosis surgery. Clin Orthop 1988; 229: 88-93.

7 Salem MR, Klowden AJ. Anesthesia for pediatric orthopedic surgery. In: Gregory GA (Ed.). Pediatric Anesthesia. New York: Churchill Livingstone, 1989; 1203-71.

8 Johnson RG, Murphy $M$, Miller $M$. Fusions and transfusions: an analysis of blood loss and autologous replacement during lumbar fusions. Spine 1989; 14: 358-62.

9 Tonnesen AS. Crystalloids and colloids. In: Miller RD (Ed.). Anesthesia, 3rd ed. New York: Churchill Livingstone, 1990; 1439-65.

10 de Castro J, Van De Water A, Wouters $L$, Xhonneux $R$, Reneman $R, K a y B$. Comparative study of cardiovascular, neurological and metabolic side-effects of eight narcotics in dogs. Acta Anaesthesiol Belg 1979; 30: 5-99.

11 Davis PJ, Cook DR, Stiller RL, Davin-Robinson KA. Pharmacodynamics and pharmacokinetics of high-dose sufentanil in infants and children undergoing cardiac surgery. Anesth Analg 1987; 66: 203-8.

12 Murat I, Delleur MM, Loose JP, Saint-Maurice C. Hypo- 
tension contrôlée dans les arthrodèses vertébrales par voie postérieure, intérêt de l'association isoflurane-trinitrine. Cah Anesthesiol 1986; 34: 117-24.

13 Fromes Y, Morin JP. Le saignement dans le traitement chirurgical des scolioses neurologiques. Place de l'hypotension contrôlée. Cah Anesthesiol 1989; 37: 493-501.

14 Bailey TE Jr, Mahoney OM. The use of banked autologous blood in patients undergoing surgery for spinal deformity. J Bone Joint Surg Am 1987; 69A: 329-32.

15 Pouliquen JC, Jean N, Noat M, Boyer J-M, Yannoutsos $H$. Les économies de sang en orthopédie pédiatrique. Etude à propos de 145 arthrodèses vertébrales postérieures. Chirurgie 1990; 116: 303-11.

16 McNeill TW, DeWald RL, Kuo KN, Bennett EJ, Salem $M R$. Controlled hypotensive anesthesia in scoliosis surgery. J Bone Joint Surg Am 1974; 56: 1167-72.

17 Lawhon SM, Kahn A III, Crawford AH, Brinker MS. Controlled hypotensive anesthesia during spinal surgery: a retrospective study. Spine 1984; 9:450-3.

18 Malcolm-Smith NA, McMaster MJ. The use of induced hypotension to control bleeding during posterior fusion for scoliosis. J Bone Joint Surg Br 1983; 65: 255-8.

19 Bennett NR, Abbott TR. The use of sodium nitroprusside in children. Anaesthesia 1977; 32: 456-63.

20 Bennett EJ, Salem MR, Sakul P, Dalal FY, McNeill TW, DeWald $R L$. Induced hypotension for spinal corrective procedures. Middle East J Anesthesiol 1974; 4: 177-86.

21 Brodsky JW, Dickson JH, Erwin WD, Rossi CD. Hypotensive anesthesia for scoliosis surgery in Jehovah's Witnesses. Spine 1991; 16: 304-6.

22 Porter SS, Asher M, Fox DK. Comparison of intravenous nitroprusside,nitroprusside-captopril, and nitroglycerin for deliberate hypotension during posterior spine fusion in adults. J Clin Anesth 1988; 1: 87-95.

23 Knight PR, Lane GA, Nicholls $M G$, et al. Hormonal and hemodynamic changes induced by pentolinium and propranolol during surgical correction of scoliosis. Anesthesiology 1980; 53: 127-34.

24 Grundy BL, Nash CL Jr., Brown RH. Arterial pressure manipulation alters spinal cord function during correction of scoliosis. Anesthesiology 1981; 54: 249-53.

25 Kling TF Jr., Wilton $N$, Hensinger RN, Knight PR. The influence of trimethaphan (Arfonad) induced hypotension with and without spine distraction on canine spinal cord blood flow. Spine 1986; 11: 219-24.

26 Brodkey JS, Richards DE, Blasingame JP, Nulsen FE. Reversible spinal cord trauma in cats. Additive effects of direct pressure and ischemia. J Neurosurg 1972; 37: 591-3. 